\title{
O paradigma indiciário e as ciências humanas: psicanálise e análise do discurso
}

\section{The indiciary paradigm and human sciences: psychoanalysis and discourse analysis}

\section{El paradigma indiciario y las ciencias humanas: psicoanálisis y análisis del discurso}

\author{
Leda Verdiani Tfouni* \\ Universidade de São Paulo - USP, Ribeirão Preto, São Paulo, Brasil
}

Katia Alexsandra dos Santos**

Universidade de São Paulo - USP, Ribeirão Preto, São Paulo, Brasil

Juliana Bartijotto***

Universidade de São Paulo - USP, Ribeirão Preto, São Paulo, Brasil

\section{Juliana Cristina Silva $* * * *$}

Universidade de São Paulo - USP, Ribeirão Preto, São Paulo, Brasil

\begin{abstract}
RESUMO
O objetivo deste artigo é propor uma abordagem teórico-metodológica em Psicologia que parte da articulação entre duas áreas do conhecimento: a Análise do Discurso pêcheutiana $(A D)$ e a Psicanálise lacaniana. Em contraste com o paradigma galileano, essas áreas são tomadas com base no paradigma indiciário (Ginsburg,1986), pelo fato de partirem de pistas para chegar aos efeitos do discurso e do inconsciente. A análise se dá a partir da mobilização de um dispositivo teórico que se organiza em função do corpus e constitui o dispositivo analítico. São mobilizados conceitos da $A D$, e a Psicanálise comparece como parte do dispositivo teórico, considerando a dimensão inconsciente na análise. Para ilustrar, apresentamos um fragmento de análise que articula as duas áreas.
\end{abstract}

Palavras-chave: paradigma, psicanálise, discurso.

\begin{abstract}
This article intends to promote a theoretical-methodological approach in Psychology, which departs from the articulation between two fields of knowledge: Pêcheux's Discourse Analysis (DA) and Lacan's Psychoanalysis. Contrary to the Galilean paradigm, these two approaches are affiliated to the Indiciary paradigm of science, because they depart from material and visible clues in order to attain the effects of the discourse and the unconscious. The analysis is carried out by mobilization of a theoretical display, organized around a corpus and constitutes the analytical display. Concepts from DA are mobilized, and Psychoanalysis contributes as a part of the theoretical
\end{abstract}


display, considering the dimension of unconscious. As an illustration, a fragment of analysis is presented.

Keywords: paradigm, psychoanalysis, discourse.

\section{RESUMEN}

El objetivo de este artículo es proponer un abordaje teórico-metodológico en Psicología que parte de la articulación entre dos áreas de conocimiento: el Análisis del Discurso pecheutiano (AD) y el Psicoanálisis lacaneano. En contraste con el paradigma galileano, estas aéreas son tomadas con base en el paradigma indiciario (Ginsburg, 1986), por el hecho de partir de pistas para llegar a los efectos del discurso y del inconsciente. El análisis se da a partir de la movilización de un dispositivo teórico que se organiza en función del corpus y constituye el dispositivo analítico. Son movilizados conceptos del $A D$, y el Psicoanálisis comparece como parte del dispositivo teórico, considerando la dimensión inconsciente en el análisis. Para ilustrar, presentamos un fragmento de análisis que articula las dos aéreas.

Palabras clave: paradigma, psicoanálisis, discurso.

\section{Introdução}

Este artigo tem como objetivo apresentar e exemplificar uma abordagem teórica e metodológica em Psicologia que parte da articulação entre duas áreas do conhecimento: a análise do discurso pêcheutiana (doravante, AD) e a Psicanálise lacaniana. Essas duas disciplinas são abordadas sob a perspectiva do paradigma indiciário, do qual trataremos na sequência.

Partimos da noção de método enquanto um conjunto de procedimentos adequados para responder a uma questão de pesquisa, e não um elemento configurado a priori (Furlan, 2008). Desse modo, entendemos que não há independência entre método, questão e teoria, todos estão imbricados: a questão da pesquisa mobiliza um modo de fazer, que constituirá o método.

Ginzburg (1986) compara alguns métodos de investigação e propõe um novo paradigma no âmbito das ciências humanas: o indiciário. Esse modelo de investigação surge como uma alternativa ao paradigma galileano, configurando-se como um modo de pesquisar aquilo que escapa à noção tradicional de ciência. Contrapondo-se à generalização, objetividade e quantificação, próprios de um modelo positivista de ciência, o paradigma indiciário traz para o campo das pesquisas a singularidade (Tfouni, 2010).

No âmbito desse paradigma a análise visa às particularidades, os indícios reveladores (pistas, dados vestigiais, signos etc.) que apontam para uma realidade complexa não experimentável diretamente, apoiando-se na possibilidade de inferi-la e interpretá-la a partir de seus efeitos. Possui como característica metodológica a não separação entre o sujeito e o objeto, considerando impossível alcançar a neutralidade. Essa postura torna possível tomar como base 
os efeitos do discurso e do inconsciente, a partir de sua materialidade, procurando observar as marcas linguísticas que levam ao gesto de interpretação do sujeito. A interpretação do pesquisador não é vista como problema, mas tomada como parte do processo de investigação e, por isso, deve ser considerada, inclusive, no que se refere à dimensão inconsciente.

A Psicanálise tem como objeto de pesquisa o inconsciente, e a AD, o discurso; ambas podem ser consideradas disciplinas indiciárias, pois não há possibilidade de entrar em contato direto com os objetos de pesquisa. Não há a possibilidade de investigar 0 discurso e o inconsciente como um objeto da realidade; o que é possível é a análise de seus efeitos: formações do inconsciente e formações discursivas.

De acordo com Pêcheux (1988), a partir dos desenvolvimentos teóricos de Marx, Freud e Saussure cria-se uma base teórica nova que, mesmo epistemologicamente heterogênea, vem abalar "... as evidências literárias da autenticidade do 'vivido', assim como as certezas 'científicas' do funcionalismo positivista" (p. 45). Desse modo, o autor coloca em causa as explicações das evidências humanas estritamente pautadas em suas ordens biológica e social, excluindo o trabalho do significante, no âmbito do simbólico, para "restituir algo do trabalho específico da letra, do símbolo, do vestígio..." (p. 45).

É importante mencionar que a dimensão da subjetividade inerente ao processo de pesquisa nesse paradigma não impossibilita o rigor e o uso da lógica; afinal, o trabalho se pauta em método sistematizado, com base em teoria consolidada, tendo por objeto formas de linguagem (objetos simbólicos).

Como a proposta deste artigo é apresentar a articulação entre a AD e a Psicanálise, a seguir discorreremos sobre esses dois modelos teóricos separadamente, para, então, apresentarmos pontos de articulação, ilustrados por vinhetas extraídas de uma análise.

\section{Psicanálise Lacaniana}

A primeira questão a ser discutida é justamente o estatuto da Psicanálise no meio cientifico, onde é relativizada a afirmação de que a Psicanálise é ciência, do mesmo modo que sua negação também é incômoda - afinal, existem pesquisadores e vasta publicação da área no campo acadêmico. Lacan (1998) faz uma releitura da obra freudiana, servindo-se de alguns pressupostos da linguística estrutural de Saussure (2006), colocando a linguagem como elemento central de sua teoria. Partindo dessa articulação, afirma o estatuto da Psicanálise enquanto ciência. No entanto, por questões de posições antagônicas sobre o que seja 'fazer ciência', há profundas 
divergências entre a Psicanálise e a ciência positivista, que se traduzem em uma impossibilidade de relacionar a Psicanálise a esse tipo de ciência, tendo em vista a divergência de objeto, de método e da concepção de real (Fink, 1998).

Freud inventa a Psicanálise a partir de casos clínicos, de modo que a teoria surge concomitante com a práxis, de forma interdependente. No entanto, há uma preocupação do autor em formalizá-la como ciência, e para isso delimita um objeto de investigação e um método de análise. No método clínico utiliza-se a associação livre de significantes para a realização da interpretação das formações inconscientes: sonhos, lapsos, atos falhos, chistes, etc. Portanto, a própria prática psicanalítica já é uma pesquisa.

Nessa ciência, não há a separação entre sujeito e objeto, porque a transferência - conceito-chave do fazer psicanalítico - está implicada em qualquer relação que envolva a linguagem. Ou seja, a transferência é um conceito proposto pela psicanálise, em que o sujeito do inconsciente repete e atualiza suas cenas fantasmáticas nas relações com o Outro e com os outros (semelhantes), e que, portanto, não ocorre somente no tratamento psicanalítico, mas em qualquer relação entre seres falantes (Nogueira, 2004).

Para Sauret (2003), há duas formas de pesquisa nesse campo: a primeira trata da pesquisa dos psicanalistas, que se sustenta no caso a caso e que apresenta resultados a partir do particular; a segunda é aquela que, não restrita à clínica, se serve dos conceitos já formulados, no intuito de investigar determinado objeto, a partir do ponto de vista dessa teoria. O método apresentado neste artigo se situa na segunda perspectiva.

Para que possamos compreender a função da Psicanálise na pesquisa que ora buscamos situar metodologicamente, é importante mencionarmos, mesmo que de forma sumária, alguns conceitos essenciais.

Para Lacan, o "inconsciente é estruturado como uma linguagem" (2008, p. 199), ou seja, toda manifestação do inconsciente coloca-se a partir, e do mesmo modo que, as práticas discursivas linguageiras, - que nos permite realizar uma analogia entre a estrutura do inconsciente e a da linguagem, proposta por Saussure (2006). A estrutura do inconsciente, portanto, se organiza em torno da cadeia de significantes, através da fala/escrita, por meio de metáforas e metonímias.

A metáfora é uma figura de linguagem fundada em relações de similaridade que intervém ao longo do eixo sincrônico da língua. $O$ princípio da metáfora consiste em designar alguma coisa por meio do nome de outra coisa, configurando-se numa substituição significante; portanto, o sentido se produz a partir do não-sentido. A metonímia é uma figura de linguagem fundada em relações de contiguidade ao longo do eixo diacrônico da língua. Caracteriza-se como um processo 
de transferência de denominação, por meio do qual o objeto é designado por um termo diferente daquele que lhe é habitualmente próprio. Esses dois termos, no entanto, podem estar ligados por uma relação de matéria a objeto ou de continente a conteúdo, ou então da relação da parte pelo todo ou da causa pelo efeito (Dor, 1992).

Lacan (2008) ao formular o axioma "um significante representa um sujeito para outro significante" (p. 203), postula dois campos: o do sujeito e o do Outro, sendo este o lugar em que se situa a cadeia significante e também um lugar onde o sujeito se presentifica. $O$ significante é o que dá suporte para a existência do sujeito - este é apenas efeito da cadeia, que sempre se apresenta como descolada das significações.

O sujeito para a Psicanálise lacaniana é da ordem do inconsciente, diferente do sujeito empírico. Para Lacan (2008), o inconsciente é o discurso do Outro e a característica do sujeito do inconsciente é de estar num lugar indeterminado. Desse modo, como efeito da cadeia de significantes e de sua história, o sujeito pode ocupar diversos lugares. O sujeito dividido é o próprio vazio de sentido, é o que emerge na hiância entre os significantes, que surge sob a forma de equívocos, atos falhos, sintomas, chistes, sonhos etc., ou seja, um acontecimento em meio a uma prática discursiva.

Assim, o analista busca interpretar não somente pelo que está dito, mas também pelo não-dito, bem como naquilo que se produz nas margens desse dizer. Isso vem acoplado à materialidade linguística, sendo parte integrante do discurso, o qual pode ser revelado pela cadeia significante naquele dado texto ou fala. Na cadeia significante não existe um sentido já dado, pois ela é formada por metáforas e metonímias, existindo uma primazia do significante sob o significado (Lacan, 1998); como consequência ocorre o deslizamento dos sentidos, a deriva e o equívoco, visto que não há sentido único.

Quando se trata da Psicanálise, é fundamental lidar com a incompletude do saber, bem como com a incerteza do resultado final. Um dos objetivos da pesquisa que utiliza o método psicanalítico é o de construir um saber que permita aos pesquisadores trabalhar seu objeto de pesquisa e elucidar o que é possível alcançar na relação entre sujeito e objeto, o que só é simbolizado a partir dos indícios, vestígios e signos.

\section{Análise do Discurso Pêcheutiana (AD)}

Pêcheux $(1988,2008)$ situa a $A D$ em um movimento de reflexão em torno da concepção de leitura/interpretação que se opôs a uma noção tradicional de leitura, baseada nas figuras do emissor/receptor, ou estabelecidas em referência à Teoria da Informação que procurava tratar os textos "objetivamente". Surge, portanto, em contrapartida a 
outras perspectivas de análise de dados de linguagem, tais como a análise de conteúdo.

A análise de conteúdo pode ser compreendida como um conjunto de instrumentos metodológicos que se aplicam a discursos (conteúdos e continentes) extremamente diversificados, ou ainda um conjunto de técnicas de análise das comunicações que podem ser quantitativas ou qualitativas, e que apostam no rigor do método. "Visa obter, por procedimentos sistemáticos e objetivos de descrição do conteúdo das mensagens, indicadores e conhecimentos relativos às condições de variáveis inferidas na mensagem" (Bardin, 1977, p. 31).

A análise de conteúdo e a $A D$ trabalham com materialidades linguísticas da mesma natureza, contudo, enquanto a primeira privilegia o conteúdo manifesto, podendo ser realizada, inclusive, como forma de transformar dados de linguagem em dados quantitativos, por meio da análise da frequência de enunciados ou expressões, a AD define um objeto diferente: o discurso, que permite olhar para os dados de linguagem não só pelo conteúdo manifesto, mas também considerando silêncios, lacunas e o próprio não-dizer, que entendemos aliado ao dito. A AD procura compreender 0 processo de produção dos sentidos em termos de condições de produção sócio-históricas.

Partindo da releitura que Althusser (1998) fez de Marx, da releitura que Lacan fez de Freud, e considerando os postulados da linguística de Saussure, Pêcheux articulou a "teoria das ideologias" ao estruturalismo linguístico, deslocando a noção de interpretação. Nesse sentido, Pêcheux cita Althusser:

Foi somente a partir de Freud que começamos a suspeitar o que significa (veut-dire) escutar e, por conseguinte, o que significa falar (ou manter-se calado); que esse "significado" (vouloir-dire) de falar e escutar revela, sob a inocência do dizer e do ouvir, as profundezas especificáveis de um nível escondido, o "significado" do discurso do inconsciente - aquele nível cujos efeitos e condições formais são pensados pela linguística moderna (Althusser, citado por Pêcheux, 1988, p. 94).

Assim, a AD é um campo que se apresenta como "área de entremeio" (Orlandi, 2007), uma vez que articula conhecimentos de distintos campos do saber, sejam eles, a Linguística, as Ciências Sociais, a Psicanálise e o Materialismo Histórico. Desse lugar teórico, estabelece um objeto próprio, o discurso, que permite compreender a linguagem enquanto lugar de manifestação do ideológico e do inconsciente onde a História incide sobre o simbólico.

A $A D$ toma como pressuposto o fato de que estudar a língua ou, nesse caso, o discurso, significa considerar as condições de produção 
(basicamente sujeitos e contexto imediato, assim como o sóciohistórico), considerando que, toda investida na linguagem passa pela observação também daquilo que lhe é exterior e, ao mesmo tempo, constitutivo, ou seja, os sujeitos, a história e a ideologia (Pêcheux, 1988).

O discurso, conceituado como "efeito de sentidos entre interlocutores", por sua vez, não é o mesmo que enunciado, texto ou dados empíricos, mas considerado como "acontecimento" (Pêcheux, 2008), organizado no tempo, em um contexto sócio-histórico e ideológico, que se produz socialmente através de sua materialidade específica (a língua) entre sujeitos.

Partindo da relação entre discurso e ideologia, convoca-se a teoria materialista, a partir da releitura de Marx por Althusser. Dessa vinculação, é trazida a noção de interpelação ideológica dos indivíduos em sujeitos e também surge a noção de interdiscurso, como aquilo que faz relação com o pré-construído, o que é dito antes, a nossa memória discursiva:

... o pré-construído corresponde ao 'sempre-já-aí' da interpelação ideológica que fornece-impõe a 'realidade' e seu 'sentido' sob a forma da universalidade (o 'mundo das coisas'), ao passo que a articulação constitui o sujeito em sua relação com o sentido, de modo que ele representa, no interdiscurso, aquilo que determina a dominação da forma-sujeito (Pêcheux, 1988 , p. 164).

A noção de sujeito e de língua(gem) é tratada por Pêcheux (1988), ainda, em referência à teoria dos esquecimentos, alargamento da noção de interpelação, análoga ao postulado freudiano do aparelho psíquico. $\mathrm{O}$ autor divide os esquecimentos em: $\mathrm{n}^{\circ} 2$, semi-consciente, da ordem da formulação, pelo qual fazemos "escolhas" na produção dos enunciados, negligenciando as outras formas que poderiam constituir o dizer; e o esquecimento no 1 , da ordem do inconsciente, é o que produz a ilusão de origem, instância que nos faz crer senhores do nosso dizer (Pêcheux, 1988, p. 173).

Pêcheux, em autocrítica impressa em fevereiro de 1978, quando apresenta seu artigo Só há causa daquilo que falha ou o inverno político francês: início de uma retificação (Pêcheux, 1988) reconhece a necessidade de considerar a falha e a falta como constitutivas da língua(gem) e do sujeito:

... o fato de que o non-sens do inconsciente, em que a interpelação encontra onde se agarrar, nunca é inteiramente recoberto nem obstruído pela evidência do sujeito-centrosentido que é seu produto, porque o tempo da produção e o do produto não são sucessivos como para o mito platônico, mas 
estão inscritos na simultaneidade de um batimento, de uma 'pulsação' pela qual o non-sens inconsciente não para de voltar no sujeito e no sentido que nele pretende se instalar (Pêcheux, 1988 , p. 300).

... o sentido é produzido no non-sens pelo deslizamento sem origem do significante, de onde há a instauração do primado da metáfora sobre o sentido, mas é indispensável acrescentar imediatamente que esse deslizamento não desaparece sem deixar traços no sujeito-ego da forma-sujeito ideológica, identificada coma evidência de um sentido (Pêcheux, 1988, p. 300).

Além dos conceitos mencionados, de discurso, sujeito e interdiscurso, outros são fundamentais para a compreensão da $A D$ enquanto metodologia de análise. São eles as noções de condições de produção, formação discursiva e formação ideológica.

As condições de produção compreendem basicamente os sujeitos e as situações: contexto imediato e histórico-ideológico. Também a memória faz parte da produção do discurso, uma vez que se compreende que todo discurso sempre está em relação com outros dizeres que circulam e que o constituem igualmente. Segundo Orlandi (2007), as condições de produção podem ser divididas em sentido estrito, que diz respeito ao contexto imediato, ou seja, às circunstâncias da produção discursiva; e em sentido amplo, que diz respeito ao contexto sócio-histórico, ideológico.

Para a $A D$, ainda, um texto faz sentido por sua inserção em uma formação discursiva (FD), em função de uma memória discursiva, do interdiscurso, que o texto retoma e do qual é parte. Assim, o discurso é uma prática social cuja regularidade só pode ser apreendida a partir da análise dos processos de sua produção e refletindo sobre a maneira como a linguagem está materializada na ideologia e como a ideologia se manifesta na língua. A formação discursiva pode ser conceituada como "aquilo que, numa formação ideológica dada, isto é, a partir de uma posição dada numa conjuntura dada, determinada pelo estado da luta de classes, determina o que pode e deve ser dito" (Pêcheux, 1988, p. 160).

As formações ideológicas, por sua vez correspondem mais ou menos aos posicionamentos de classe a partir dos quais nossa sociedade se organiza, os quais se materializam nas formações discursivas que podem ser consideradas "regionalizações" do interdiscurso, ou seja, agrupamentos, em função de alguma regularidade, de discursos que circulam culturalmente (Orlandi, 2007).

Para tratar do dispositivo de análise da $A D$, primeiramente é preciso deixar claro que todo método nessa área depende do objeto. Compreende-se que qualquer análise se inicia a partir da escolha do 
objeto discursivo e da constituição do corpus, uma vez que se leva em consideração que o(s) discurso(s) se organizam em rede, recortar algo dessa rede já é um gesto de análise. Desse modo, refuta-se a ilusão de que é possível separar processos e produtos, como se fosse possível trabalhar apenas os produtos - os dados - em si, autonomamente. $A A D$ não trabalha com as evidências, mas com o processo de produção de evidências (Orlandi, 2007), que é o efeito ideológico fundamental.

Assim, a AD opera de modo que, "... através de descrições regulares de montagens discursivas, se possa detectar os momentos de interpretações, enquanto atos que surgem como tomadas de posições, reconhecidas como tais, isto é, como efeitos de identificação assumidos e não negados" (Pêcheux, 1988, p. 57). O analista, portanto, munido de um arcabouço teórico, produz uma análise/interpretação, sem a pretensão de fazê-lo de modo objetivo, mas apenas interceptado por um dispositivo teórico que organiza um dispositivo analítico. É disso que trataremos na sequência.

\section{Dispositivos de Análise}

Cada análise é uma nova prática de leitura, na qual há mobilização de dispositivos teóricos a partir da questão formulada pelo analista. Assim, distinguimos o dispositivo teórico do analítico, conforme Orlandi (2007), mas compreendendo que ambos estão em relação. O dispositivo teórico é construído pelo analista a cada análise, ou seja, é o conjunto de formulações e conceitos dos quais lança mão em uma situação analítica. $O$ dispositivo analítico consiste na maneira como o analista utiliza, "individualiza" o dispositivo teórico, considerando a natureza do material e a finalidade da análise.

Na perspectiva da interface da AD com a Psicanálise, como estamos propondo neste artigo, a Psicanálise comparece como parte do dispositivo teórico, no qual as análises linguísticas são atravessadas pela dimensão do inconsciente.

Considerando esses dois dispositivos, uma análise se organiza a partir de duas fases de contato com a materialidade linguística: a descrição e a interpretação. A descrição incide sobre as materialidades discursivas e supõe "... o reconhecimento de um real específico sobre o qual ela se instala: o real da língua" (Pêcheux, 1988 , p. 50). Nesse sentido, a descrição passa por uma análise sintática, mas não se esgota nela, uma vez que "as regras da sintaxe comportam tanto um movimento de contenção quanto um movimento de liberdade, um jogo que permite subverter a língua e fazer emergir uma 'novidade' (metáforas, trocadilhos, lapsos, neologismos etc.) em seu próprio interior" (Tfouni \& Carreira, 2007, p.166). 
A descrição pretende, então, partir da materialidade das montagens discursivas, jogando com as regras, ao considerar essas materialidades sintaticamente, e também com as ambiguidades próprias da língua, para que, dessa forma, se possa chegar aos "... momentos de interpretações enquanto atos que surgem como tomadas de posição" (Pêcheux, 1988, p. 57) em relação a um "discurso-outro", lugar da memória histórica sempre virtualmente presente na materialidade descritível da sequência.

Descrição e interpretação, entretanto, não são duas fases sucessivas de análise, mas se processam de modo alternado. O que se busca é um trabalho que vise uma divisão discursiva entre dois espaços: o das significações estabilizadas, normatizadas, que marcam a "...insistência do outro como lei do espaço social e da memória histórica" (Pêcheux, 1988, p. 55) e o das transformações de sentido. Todo enunciado está exposto ao equívoco próprio da língua, se apresentando como uma "... série (léxico-sintaticamente determinada) de pontos de deriva possíveis, oferecendo lugar à interpretação" (Pêcheux, 1988, p. 53).

A descrição é o contato e a tentativa de percorrer o discurso, por meio do levantamento das condições de produção e da formulação de paráfrases (modos diferentes de dizer "o mesmo"). A interpretação é o gesto de leitura em que o analista procura relativizar sua posição de afetamento ideológico, procurando percorrer os gestos de construção dos discursos e as possibilidades de efeitos de sentido (Orlandi, 2007).

Embora toda análise seja singular, conforme já mencionamos anteriormente, e não seja possível, portanto, traçar um caminho de análise que sirva para todo gesto de interpretação, apresentamos a seguir um exemplo (retirado e adaptado de Tfouni, 2013) para demonstrar uma possibilidade de se articular as duas áreas que aqui apresentamos: a análise do discurso pêcheutiana e a Psicanálise lacaniana. Nesse processo de batimento entre descrição e análise, devemos considerar os seguintes procedimentos.

O primeiro refere-se à constituição do corpus. Trata-se já da primeira parte da análise, uma vez que parte da questão de pesquisa considera a subjetividade do pesquisador na determinação dos recortes considerados "representativos" do discurso que ora se pretende analisar. Geralmente a escolha do que constituirá o corpus analítico ocorre em função da regularidade com que determinados fenômenos linguísticos se apresentam ou ainda um estranhamento, quando se considera as práticas discursivas regulares.

A análise que utilizamos como instanciação neste artigo toma como corpus (material a ser analisado) um texto publicitário, que representa/ilustra parte dos discursos que circulam sobre a questão da felicidade em nossa sociedade. Nesse sentido, a partir do recorte realizado, já há um gesto analítico, uma vez que a constituição do 
corpus é um recorte do pesquisador na forma de um enunciado. Para ilustrar, retomamos Tfouni (2013), que escolhe o slogan do Magazine Luiza - uma grande rede de lojas e departamentos de varejo no Brasil: "Vem ser feliz".

A análise do corpus propriamente dita se faz em três etapas, conforme Orlandi (2007): da superfície linguística ao objeto teórico discursivo, para, enfim, se chegar ao processo discursivo. A primeira etapa corresponde à passagem da superfície linguística para o objeto teórico discursivo. Trabalhamos aqui no nível da formulação, observando a relação existente entre diferentes superfícies linguísticas face ao objeto discursivo a ser analisado. $O$ procedimento mais usual é a formulação de paráfrases.

No exemplo da análise de Tfouni (2013), a autora chama a atenção para o efeito de sentido obtido pelo uso dos significantes dêiticos:

No não dito, esse genérico propõe uma polarização entre dois lugares do mundo real, posições essas que são sustentadas discursivamente pelo caráter dêitico do verbo 'dizer': 'aqui' é o lugar da felicidade; 'aí' é o lugar da infelicidade. 'Aqui' é o lugar onde se encontra a pessoa que fala (primeira pessoa do discurso); 'aí' é o lugar do interlocutor (segunda pessoa do discurso). 'Vem ser feliz' (aqui); a forma imperativa na segunda pessoa remete ao interlocutor (público alvo); sujeito sintático do enunciado (tu) está contido na própria forma do verbo 'vir', mas o sujeito da enunciação não fica evidente. Quem é esse sujeito não identificado? Uma resposta possível seria afirmar que aí, nesse lugar vazio, temos a voz do Outro representante do desejo (Tfouni, 2013, p. 06).

A segunda etapa corresponde à passagem do objeto teóricodiscursivo ao processo discursivo, por meio das formações discursivas que estão em jogo na produção dos sentidos. Para isso, observam-se os diferentes gestos de interpretação e o delineamento das distintas formações discursivas. Nesta etapa, no exemplo, as formações discursivas são delimitadas através da referência ao interdiscurso:

Assim, o sentido do dizer está implícito na formação discursiva de uma ideologia da classe dominante que manipula e aliena, através de compulsivos apelos para o consumo. Na peça discursiva "Vem ser feliz", o pressuposto é que é preciso consumir para ser feliz, ou ainda que o consumo seria a única fórmula para ser feliz e vencer (na vida?). Numa operação metafórica, substitui-se mercadoria por felicidade. (Tfouni, 2013, p. 07). 
Na terceira etapa ocorre a passagem das formações discursivas para as formações ideológicas devido à inscrição do interdiscurso, em última instância a análise discorre sobre os possíveis efeitos do discurso e da ideologia na forma-sujeito e no sujeito do inconsciente:

Portanto a palavra ordem 'vem ser feliz (aqui onde estou)' tem o efeito de sentido de fazer o sujeito consumidor acreditar que existe um lugar próprio onde a felicidade está; que tal lugar não coincide com o do consumidor; que o lugar onde o consumidor está não o faz feliz [...]. No discurso oral, o sintagma 'vem ser' é também ouvido como seu homônimo 'vencer'. Vencer e ser feliz: o ideal completo do sujeito moderno - hedonismo e competição. Além disso, a peça promocional acrescenta o nome desse lócus da felicidade: Magazine Luiza (Tfouni, 2013, p. 07).

Tfouni (2013) ainda acrescenta que a promessa embutida no slogan concretiza a ideia de que há um lugar onde é possível ser feliz. No entanto, o desejar é a peça fundamental do discurso capitalista, ou seja, esse sistema se sustenta na promessa de felicidade e na não satisfação do sujeito, para que ele continue no lugar de consumidor. O que fica recalcado "... são espaços de compras, e que a mercadoria, nas sociedades capitalistas tardias, é confundida com felicidade" (Tfouni, 2013, p. 07).

Ao final dessa apresentação, ressaltamos que a separação em etapas não ocorre de modo linear e unilateral, mas de forma entrelaçada. A apresentação em etapas separadas, como trouxemos, neste texto, reflete apenas uma tentativa de formalizar de modo mais didático o processo de análise em AD e Psicanálise. É precisa ressaltar também que outro pesquisador poderia exercer um gesto de interpretação diferente em relação a essa mesma superfície linguística.

\section{Considerações Finais}

A perspectiva metodológica que trouxemos ancora-se no paradigma indiciário (Ginsburg, 1986). Tomamos como aportes teóricometodológicos a $A D$ e a Psicanálise lacaniana, áreas que nos permitem olhar para nossos objetos de modo a interpretá-los e produzir/percorrer os sentidos possíveis que eles nos apresentam, tendo o pesquisador papel fundamental nesse processo. Alguns elementos comuns que podemos elencar na abordagem das áreas e do método delas derivado são: o primado do simbólico como fonte de dados, a consideração da subjetividade, da singularidade e a interpretação. 
Os limites desse modo de pesquisa aparecem, sobretudo, quando relacionamos nossa perspectiva ao paradigma galileano. Assim, não trabalhar com o observável pode ser tido como um problema para a própria cientificidade da pesquisa, uma vez que não é possível a reprodução, já que não fazemos experimentos e não lidamos com variáveis que possam ser manipuladas. Também não há etapas claras, pré-definidas no caminho a ser percorrido pelo pesquisador, o que pode consistir em um problema, sobretudo para pesquisadores iniciantes ou inexperientes na área. Algumas críticas, ainda, apontam o tipo de amostra que trabalhamos como "amostra teórica" (Campos, 2008), que pode ser tendenciosa, uma vez que provavelmente, não irá contradizer a tese defendida pelo autor.

Entendemos, no entanto, que a proposta metodológica apresentada considera o contato com sujeitos/textos/discursos na pesquisa, tomando a constituição do corpus como parte fundamental de uma análise que já se inicia nesse momento. Interessa-nos a profundidade nas análises e a consideração do pesquisador como parte do universo pesquisado. A representatividade do corpus não depende da quantidade de dados coletados e analisados, já que interessa ao pesquisador o processo discursivo, que vai além do material de análise em si. O fato de trabalhar com elementos não-observáveis nos coloca, ainda, em um lugar de investigação privilegiado, já que trabalhamos com fatos essencialmente humanos, voltados à linguagem e que se colocam como elementos de interesse para a comunidade científica nas ciências humanas.

\section{Referências}

Althusser, L. P. (1998). Aparelhos ideológicos de Estado. (7a ed.). Rio de Janeiro: Graal. (Trabalho original publicado em 1964).

Bardin, L. (1977). Análise de conteúdo. Lisboa: Edições.

Campos, L. F. L. (2008). Métodos e técnicas de pesquisa em Psicologia. (4a ed.). Campinas: Alínea.

Dor, J. (1992). Introdução à leitura de Lacan: o inconsciente estruturado como linguagem. Porto Alegre: Artmed.

Fink, B. (1998). O sujeito lacaniano: entre a linguagem e o gozo. Rio de Janeiro: Jorge Zahar.

Furlan, R. (2008). A questão do método na Psicanálise. Psicologia em Estudo, 13(1), 25-33. Recuperado de http://www.scielo.br/pdf/pe/v13n1/v13n1a03.pdf

Ginzburg, C. (1986). Sinais: raízes de um paradigma indiciário. In C. Ginzburg, Mitos, emblemas e sinais (pp. 143-179). São Paulo: Companhia das Letras.

Lacan, J. (1998). A instância da letra no inconsciente ou a razão desde Freud. In J. Lacan, Escritos (V. Ribeiro, Trad.). Rio de 
Janeiro: Jorge Zahar. (pp. 496-533). (Trabalho original publicado em 1957).

Lacan, J. (2008). O seminário: livro 11: os quatros conceitos fundamentais da Psicanálise. (2a ed.). (V. Ribeiro, Trad.). Rio de Janeiro: Jorge Zahar. (Seminário ministrado em 1964/1965).

Nogueira, L. C. (2004, junho). A pesquisa em Psicanálise. Psicologia USP, 15(1-2), 83-106. Recuperado de http://www.scielo.br/pdf/pusp/v15n1-2/a13v1512.pdf

Orlandi, E. P. (2007). Análise de discurso: princípios e procedimentos. (7a ed.). Campinas: Pontes.

Pêcheux, M. (1988). Semântica e discurso: uma crítica à afirmação do óbvio. (4a ed.). (E. P. Orlandi, Trad.). Campinas: Editora da Unicamp. (Trabalho original publicado em 1975).

Pêcheux, M. (2008). O discurso: estrutura ou acontecimento. (5a ed.). (E. P. Orlandi, Trad.). Campinas: Pontes. (Trabalho original publicado em 1981).

Sauret, M.-J. (2003). A pesquisa clínica em Psicanálise. Psicologia USP, 14(3), 89-104. Recuperado de http://www.scielo.br/pdf/pusp/v14n3/v14n3a09.pdf

Saussure, F. (2006). Curso de linguística geral. (2a ed.). São Paulo: Cultrix. (Trabalho original publicado em 1916).

Tfouni, L. V., \& Carreira, A. F. (2007, julho). O sujeito submetido à linguagem. Investigações, 20(2), 153-171. Recuperado de http://www.revistainvestigacoes.com.br/Volumes/Vol.20.N.2_2 007_ARTIGOSWEB/LedaAutor-AlessandraFernandes_OSUJEITO- SUBMETIDO-A-LINGUAGEM_Vol20-N2_Art09.pdf

Tfouni, L. V. (2010). Letramento e alfabetização. (9a ed.). São Paulo: Cortez.

Tfouni, L. V. (2013). Em busca da felicidade, o corpo se consome no consumo. Revista Távola online. Recuperado de http://nucleotavola.com.br/revista/em-busca-da-felicidade-ocorpo-se-consome-no-consumo/

\section{Endereço para correspondência \\ Leda Verdiani Tfouni}

Universidade de São Paulo - USP

Faculdade de Filosofia, Ciências e Letras de Ribeirão Preto (FFCLRP-USP)

Av. Bandeirantes, 3900, Monte Alegre, CEP 14040-901, Ribeirão Preto - SP, Brasil

Endereço eletrônico: Ivtfouni@usp.br

\section{Katia Alexsandra dos Santos}

Universidade Estadual do Centro-Oeste - UNICENTRO

Departamento de Psicologia

PR 153, Km 7, s/n, Riozinho, CEP 84500-000, Irati - PR, Brasil

Endereço eletrônico: kalexsandra@yahoo.com.br

\section{Juliana Bartijotto}

Universidade de São Paulo - USP

Faculdade de Filosofia, Ciências e Letras de Ribeirão Preto (FFCLRP-USP) 
Av. Bandeirantes, 3900, Monte Alegre, CEP 14040-901, Ribeirão Preto - SP, Brasil Endereço eletrônico: jubartijotto@gmail.com

\section{Juliana Cristina Silva}

Universidade de São Paulo - USP

Faculdade de Filosofia, Ciências e Letras de Ribeirão Preto (FFCLRP-USP)

Av. Bandeirantes, 3900, Monte Alegre, CEP 14040-901, Ribeirão Preto - SP, Brasil

Endereço eletrônico: ana_juliana25@yahoo.com.br

Recebido em: $21 / 06 / 2015$

Aceito para: 25/07/2016

\section{Notas}

* Professora titular, departamento de Psicologia, Universidade de São Paulo.

** Pós-doutoranda em Psicologia pela USP, professora do departamento de Psicologia na UNICENTRO.

*** Psicanalista, mestre em Psicologia pela Faculdade de Filosofia, Ciências e Letras de Ribeirão Preto-USP.

**** Mestre em Psicologia pela Faculdade de Filosofia, Ciências e Letras de Ribeirão Preto-USP. 